Original research article

doi: 10.3126/njiss.v3i3.36463

\begin{tabular}{llll}
\hline Volume 3 & Issue 3 & Dec 2020 & 2565-4942 (Print) 2738-9693 (online) \\
\hline
\end{tabular}

\title{
Impact of Lapsed Policies in Life Insurance Industries of Nepal
}

\author{
Ram Koju, Public Administration Campus, Tribhuvan University, Kathmandu, Nepal \\ Corresponding author email: kojuram5@gmail.com \\ Susil Dev Subedi, Phd Scholar, Central Department of Economics, Tribhuvan University, \\ Kathmandu, Nepal \\ Laxmi Koju, Researcher, Academy of Mathematics and Systems Science, Chinese Academy of \\ Sciences, Beijing 100190, China
}

\begin{abstract}
Growth and competition are rapidly rising in life insurance sector. Companies have challenge to stay in the market and earn profit as well as build trust among the end users. In this context, companies have to expand business by selling more life insurance policies. However, only selling new policies might not be the solution to increase profit. Thus, company needs to ensure minimum to zero lapse rates for the sustainable growth of the company. This study investigated the impact of lapse rate and revival rate on net worth, profitability, life fund, and total premium income of life insurance industries in Nepal over the period 2010-2019. The study employed Generalized Method of Moments (GMM) for empirical estimation. The empirical results showed the lapse rate, profitability, revival rate and surrender rate of $23.91 \%, 2.64 \%, 88.82 \%$ and $3.83 \%$, respectively in the life insurance industries in Nepal during the 10 years' period. The lapse rate was significantly negatively correlated with life fund and the total premium income with the-model coefficients of 0.1474065 and -0.19244, respectively. Moreover, the empirical estimation showed a significant positive correlation between lapse rate and profitability. This might be because high lapse rate lowers the provision of unexpired risk and life fund resulting in higher amount of profitability. The revival rate was significantly positively correlated with the profitability. This might be because higher revival rate increases the renewal income of a company, resulting in more funds available for investment thereby bringing positive cash inflow for the company. However, the revival rate did not show any significant association with net worth, life fund and total premium income.
\end{abstract}

Keywords: Augmented Dickey-Fuller test, Generalized Method of Moments, JarqueBerra test, Revival Rate, Surrender Rate

$64 \sim$ Koju, Subedi \& Koju 
Volume 3 Issue $3 \quad$ Dec $2020 \quad$ 2565-4942 (Print) 2738-9693 (online)

\section{Introduction}

Insurance is a risk mobilization technique through the scientific study of risk profiling. The insurance sector plays an important role in the service-based economy and its services are now being integrated into wider financial industry (Malik, 2011). By exploring the risks (financial) associated with the people and society, insurance contributes to the economic growth by nurturing the long term investment through the capital collected from accumulated savings from individuals. Precisely, insurance as a risk indemnifier and financial intermediary can promote economic growth by managing risk in a more effective way and by mobilizing domestic savings in long term investment (Ward \& Zurbruegg, 2000). Both life and non-life insurance companies collect scattered savings from ordinary people and create capital for the nation.

A typical life insurance contract provides a package of options or rights to the policy owner that is not precisely duplicated by any other combination of commonly available contracts. Viewed from this perspective, life insurance enjoys a unique position in the field of investments and should be judged in this light (Smith, 1982). Life insurance policies offer capital preservation and growth, as well as protection, depending on the product type (Poufinas \& Michaelide, 2018). Life insurance collects premium from policyholders against their risk. If any default occurs or if the policy term matures, whichever comes first, the insurer is liable to pay the predefined amount. This is the general working principle of a life insurance company. Now the question comes, what if the policy holders are unable to pay premium after a certain time interval. What impact does it exert on the life insurance company? If policy holders are unable to pay their premium, it becomes a lapse policy within a specific period. If a policy holder restates such lapse policy under predefined guideline, it then becomes a revive policy and the risk coverage of the insured continues.

Lapse rate is the rate at which life insurance policies terminate because of failure to pay the renewal premiums by the policy holders on stipulated dates. Lapses influence the profitability and liquidity of insurance companies through acquisition cost, loss of income from renewal premiums etc and hence needs to be controlled and managed carefully (Vidyavathi, 2013). More specifically, lapse rate refers to the number of lapse policy upon the total issued policy and the revival rate refers to the revived policy upon the total lapse policy for the period. 
There might be various internal and external reasons for lapse polices in life insurance industries. Some of the major internal reasons might be 'force selling' and 'miss-selling', while the external reasons might be economic condition and policyholders' behavior. Whatever might be the reasons; such lapses have negative impact on the premium collection and networth of a life insurance company.

Life Insurance sector in Nepal is significantly rising. Awareness and importance of life insurance is also significantly growing. Growth and competition are rapidly rising in life insurance sector. In such market place, sustainable growth and development of life insurance industries is very crucial. However, in Nepal, the studies on sustainable growth in life insurance sector are limited and the quantitative evaluation is largely lacking. Therefore, it is crucial to examine the lapse policies and the revival rates in the life insurance sectors as well as evaluate the impact of lapse rate and revival rate on net worth, life fund and profitability of the insurance companies to ensure their sustainable growth.

Companies have challenge to stay in the market and earn profit as well as build trust among the end users. In this context, companies have to expand business by selling more life insurance policies. However, only selling new policies might not be the solution to increase profit. Thus, company needs to ensure minimum to zero lapse rates for the sustainable growth of the company. Thus, this study was carried out to find out the lapse rate and its impact on profitability, net worth, life fund and total premium income, which will add value to achieve sustainable growth and expansion of the life insurance industry.

The study is based on the descriptive analyses of lapse policies in life insurance sector in Nepal in terms of number and premium and its impact on net worth, life fund and profitability over a 10 years period (2010-2019). The study attempts to examine the magnitude and trend of lapse rate, revival rate and surrender rate in the life insurance industries in Nepal. Moreover, the study examines the impact of lapse rate and revival rate on net worth, life fund, profitability and total premium income. The study also makes comparative examination of lapse rate, revival rate, surrender rate, life fund, profitability, net worth and total premium income. The findings are expected to add value to the policyholders, the insurer and mainly to the regulator for effective supervision and risk management of overall life insurance industry.

$66 \sim$ Nepalese Journal of Insurance and Social Security 
The study included the economic and panel data collected from Beema Samiti. Data related to lapse rate, revival rate, surrender rate and profitability were collected on an annual basis. The study is limited to the period from 2010 to 2019 AD. A panel data consisting of 17 cross sections (insurance company) covering a 10-year period is used for this study.

\section{Literature review}

Fier and Liebenberg (2013) found that voluntary lapses are related to large income shocks, and consistent with the policy replacement hypothesis. The decision to lapse of life insurance policy is directly related to the purchase of a different life insurance policy. Their study also found that age is an important moderating factor in the lapse decision. Changes in income appear to_directly affect the lapse decision more for younger households while they are generally unrelated to the lapse decision for older households. This implies that income and age of the insured have predominant impact on the lapse decision of life insurance policies.

Vidyavathi (2013) found that lapses influence the profitability and liquidity of insurance companies through acquisition cost, loss of income from renewal premiums and hence needs to be controlled and managed carefully. Lapse rate is an important ratio for insurance companies providing life insurance products for the customers. Lapse rate constitutes one of the main indicators to assess the product and service quality of the insurers.

Mall and Sahoo (2015) found that product characteristics i.e. sum insured, product type, outstanding premium, mode of payment, policy duration, outstanding policy duration, and the policyholder characteristics, such as age of the policyholder, occupation, dependency, and marital status, are significant determinants of lapsation. Their study shows a better depiction of the lapse drivers and is expected to help insurance companies and other intermediaries to understand lapsation.

Subashini and Velmurugan (2015) found that miss-selling of the product, financial burden to the policyholders and high premium rates are the major determinants of lapsation in Indian insurance market. They found that, because of these factors, in spite of rapid progress, insurance sector in India is suffering with high rate of lapsation. 
Kiesenbauer (2012) found that the major determinants of lapse policies are very similar across all product categories, except that the direction of impact is reversed for the product category "other" among five different product categories (endowment, annuity, term life, group and other) which consists almost exclusively of unit-linked business. In particular, the interest rate and emergency fund hypotheses are only supported for unit-linked business, while these hypotheses do not hold for the remaining product categories. Overall, the analysis provides an understanding of lapse dynamics related to economic indicators and company characteristics. Subashini and Velmurugan (2016) found that the foremost problem faced by insurance industry sector is the growth of lapsation rate. The main reason for the lapse in insurance policies is miss-selling, unfair business practice, delay in claim settlement and poor policy servicing. Miss-selling complaints is the dominant kind of grievances in the life insurance industry (IRDAI Annual Report 2014-15).

Yu, Cheng, and Lin (2019) found that the unemployment rate is positively related to lapse rates, and the driving force is migrant population rather than local urban residents. Insurer's reputation is negatively linked to lapse rates. Interest rates are positively (negatively) associated with lapse rates of investment-type (protection-type) products. Lapse rates of health products are not related to interest rates. Fourth, empirical result suggests that high lapse rates can potentially weaken the insurers' financial soundness and harm new business.

Kuo, Tsai, and Chen (2003) found that the unemployment rate affects the lapse rate in both the long and short run, whereas the interest rate causes variations in the lapse rate mainly in the long run. The interest rate hypothesis is favored against the emergency fund hypothesis in the sense that the interest rate is more economically significant than the unemployment rate in explaining the lapse rate dynamics.

Belth (1968) found that lapse rates have a substantial effect on price, and that consideration should be given to the use of expected lapse experience in the classification of life insurance applicants.

$68 \sim$ Nepalese Journal of Insurance and Social Security 
Parihar (2020) found that sum assured value significantly differed in public and private insurance sector across the time span. Public sector insurance companies are paying higher amount then the private sector. Considering various time for the study, the same technique reveals that the guaranteed amount paid to the policyholder in various years is different throughout the time span. But at the same time lapse ratios do not show any significant difference in public and private sector across the time. Lapse ratios are same across the sectors and also across the various time.

\section{Methodology}

\subsection{Data sources}

In the present study, we examined the impact of Lapse Rate (LR), Revival Rate (RR) on profitability (ROA), Net Worth (NW), Life Fund (LF), TPI (Total Premium Income) of 17 life insurance companies in Nepal for the period 2010-2019. Out of 19 life insurance companies, 17 life insurance companies were taken as the sample due to data availability. This study has taken Return on Assets (ROA) as the proxy of profitability. This is expressed in percentage and taken as dependent variables for the entire study. Different experimental variables were used to analyze the impact of LR, RR and SR on Profitability, Net worth, Life fund and TPI. The main focus of our study was to find a linkage between LR, RR and ROA, NW, LF and TPI in life insurance industries in Nepal.

The annual financial data relating to ROA, NW, LF, TPI, FPI, LR, RR, SR for a 10-year period were taken from the concerned companies itself. This study solely relied on the secondary source of data collected from Beema Samiti.The choice of variables and time period were determined based on data availability. A brief discussion and background of variables used in this study are summarized in Table 1. 
Volume 3 Issue $3 \quad$ Dec $2020 \quad$ 2565-4942 (Print) 2738-9693 (online)

Table 1: Description of variables and their sources

\begin{tabular}{|c|c|c|c|}
\hline Variable & Explanation & Source of data & Period \\
\hline Lapse rate (LR) & $\begin{array}{l}\text { No. of Lapse policies/No. } \\
\text { of policies issued }\end{array}$ & Beema Samiti & 2010-2019 \\
\hline Revival rate (RR) & $\begin{array}{l}\text { No. of revived } \\
\text { policies/No. of lapse } \\
\text { policies }\end{array}$ & Beema Samiti & 2010-2019 \\
\hline Profitability (ROA) & $\begin{array}{l}\text { Return on Assets in } \\
\text { percentage }\end{array}$ & Beema Samiti & 2010-2019 \\
\hline Net-worth (NW) & Amount in millions & Beema Samiti & 2010-2019 \\
\hline Life fund (LF) & Amount in millions & Beema Samiti & 2010-2019 \\
\hline First premium income (FPI) & Amount in millions & Beema Samiti & 2010-2019 \\
\hline $\begin{array}{l}\text { Total first premium income } \\
\text { (TPI) }\end{array}$ & Amount in millions & Beema Samiti & 2010-2019 \\
\hline Surrender rate (SR) & $\begin{array}{l}\text { No. of surrendered } \\
\text { policies/No of issued } \\
\text { policies }\end{array}$ & Beema Samiti & 2010-2019 \\
\hline
\end{tabular}

\subsection{Research variables}

Based on existing literatures, we selected lapse rate (LR), revival rate (RR), and surrender rate (SR) as independent variables and the profitability (ROA), life fund (LF), net worth (NW), first premium income (FPI) and total premium income (TPI) as dependent variables.

\subsubsection{Dependent variables}

ROA is a common tool to measure profitability of a company. ROA gives an idea as to how efficient a company's management is at using its assets to generate earnings. A higher ratio 
implies that the available sources and tools are employed efficiently. The formula to calculate ROA is as follows:

$$
\frac{\text { Net Profit after tax - Preference Dividend }}{\text { Total Assets }}
$$

Net Worth is defined as the assets minus liabilities of an individual and company. It is a measure of what an entity is worth. Relatively high net worth signifies a good financial strength and ultimately good credit rating of an individual or a company. Similarly, a low or negative net worth signifies a weak financial strength and a low credit rating. It can be calculated as:

Net worth $=$ Paid up Capital + Reserve and surplus fund + Catastrophic fund + -write off expense -Loss transfer from P/C account

Life insurance fund means the fund established under section 18 of Directive"Financial statement of life insurer" issue dated 2068/03/10 BS. Life fund is the sum obtained from the revenue account of the insurer after deduction of payment in respect of business are made. Life fund is also called Life Assurance Fund. It is placed on the liability side of the company's Balance Sheet.

First Premium Income (FPI) is the initial (first) amount paid by the policyholder to the insurer as the premium for the policy.

Total Premium Income (TPI) is the amount received by the insurance company as premium from new and old policyholders as first premium and renewal premium income. TPI can be calculated as:

$$
\mathrm{TPI}=\mathrm{FPI}+\text { Renewal Premium Income (RPI) }
$$

Higher the TPI and FPI, bigger the company size, growth and LF and NW.

\subsubsection{Independent variables}

Based on existing literature, we regarded LR, RR \& SR as independent variables in this study and we attempt to examine the impact of these variables on ROA, LF, NW, TPI and FPI. 
Lapse rate explains how many policyholders fail to renew their insurance policy during the period. It is an amount of the number of policies issued by an insurance company that are not renewed (including forfeiture policy) divided by the number of policies that were enforced at the period. The ratio serves as an imperative tool in the insurance industry because it discloses how efficient a company is at retaining its customers and earnings. Lapsed policies differ from canceled policies. For the present study lapse rate is calculated as follows:

\section{Number of lapse policy (Inculding forfeiture policy) for the period}

Total number of policy issue for the period

Revival rate refers to the number of reinstated policies by the policyholder (starting their risk coverage from policy after lapse) relative to the number of lapse policy during the year. This ratio explains what percentage of lapse policies is being reinstated or revived during the period. This ratio indicates the efficiency and ability of a company to retain its old customers. The revival rate is calculated as follows:

Number of revive policy for the period Number of lapse policy (inculding forfeiture policy) for the period

Surrender rate indicates the number of terminated policies by the policyholders other than the maturity claims. Higher SR has negative impact on the company's profitability and sustainability as well as public branding and trust. Lower SR implies high people trust as well as sound financial sustainability. Generally, lower surrender rate is preferred in a life insurance industry. The surrender rate is calculated as follows:

Number of surrender policy for the period

Total number of policy issue for the period

\subsection{Normality test}

The study investigated whether the variables followed the normal distribution. This study relied on the Jarque-Berra (JB) test where a null hypothesis of normality was tested against the alternative hypothesis of non-normal distribution. For normal distribution, the JB statistic was expected to be statistically indifferent from zero.

$H_{0}: \mathrm{JB}=0$ (normally distributed)

$72 \sim$ Nepalese Journal of Insurance and Social Security 
$H_{1}: \mathrm{JB} \neq 0$ (not normally distributed)

Rejection of the null for any of the variables would imply that the variables were not normally distributed and a logarithmic transformation was necessary.

\subsection{Econometric specification}

Prior to estimation, the test for non-stationary (unit root) was performed by employing the Augmented Dickey-Fuller (ADF) test and Levin, Lin and Chu test (Levin, Lin, \& Chu, 2002)in order to determine the integration of variables and to avoid the spurious regression coefficients. The unit root test results (see Table 2) show that all variables are stationary after second differencing.

Table 2: Panel unit root test results

\begin{tabular}{lcccc}
\hline Variables & $\begin{array}{c}\text { ADF - Fisher } \\
\text { Chi-square }\end{array}$ & p-value & $\begin{array}{c}\text { Levin, Lin \& } \\
\text { Chu test }\end{array}$ & p-value \\
\hline Lapse rate (LR) & 34.4374 & 0.0047 & -5.32306 & 0.000 \\
Revival rate (RR) & 58.6324 & 0.000 & -7.21141 & 0.000 \\
Surrender rate (SR) & 86.9079 & 0.000 & -9.55507 & 0.000 \\
Net worth (NW) & 51.1436 & 0.000 & -7.64639 & 0.000 \\
Life fund (LF) & 84.799 & 0.000 & -8.45212 & 0.000 \\
Profitability (ROA) & 83.3612 & 0.000 & -11.5969 & 0.000 \\
Total first premium (TPI) & 62.4433 & 0.000 & -10.4275 & 0.000 \\
\hline
\end{tabular}

The past studies encourage designing a dynamic panel model for consistent estimation of parameters. The lagged dependent variable is treated as a regressor on the right-hand side to show some degree of persistence in the level of LR and RR, respectively.

$$
Y_{i t}=\alpha Y_{i t-1}+\beta X_{i t}+\eta_{i}+\varepsilon_{i t},|\alpha|<1, \mathrm{i}=1 \ldots . ., \mathrm{N}, \mathrm{t}=1 \ldots . . \mathrm{T}
$$

Here, subscripts $i$ and $t$ denote the cross-sectional and time dimension of the panel, respectively. $Y_{i t}$ is the vector of dependent variables (NW, LF, ROA and TPI). $Y_{i t-1}$ is the vector of lagged dependent variables. $X_{i t}$ is either lapse rate or revival rate. $\alpha$ and $\beta$ are the vector of coefficients 
to be estimated. $\eta_{i}$ is the unobserved company-specific effect and $\varepsilon_{i t}$ is the error term. The equation (I) assumes that the error term $\varepsilon_{i t}$ satisfies the orthogonality conditions.

In equation (I), $Y_{i t-1}$ is correlated with the fixed effects, which is called the dynamic panel bias that cannot be solved by the static panel data models. In the presence of lagged dependent variable, Ordinary Least Square estimation gives upward biased results. Similarly, the random effects estimator gives downward biased results in the dynamic panel data model (Baltagi, 2008). The within-group estimators also cannot solve the dynamic panel bias (Bond, 2002; Nickell, 1981). The Generalized method of moments (GMM) proposed by Arellano and Bond (1991) and generalized by Arellano and Bover (1995) and Blundell and Bond (1998) are found to be more efficient in solving the dynamic panel bias. These general estimators address such problems by first-differencing the equation (I)as follows.

$$
\Delta Y_{i t}=\alpha \Delta Y_{i t-1}+\beta \Delta X_{i t}+\Delta \varepsilon_{i t} \ldots \ldots \ldots \ldots \ldots \ldots \ldots \ldots \ldots \ldots \ldots \ldots \ldots \ldots \ldots \ldots \ldots \ldots \ldots \text { (II) }
$$

In equation (II), the fixed effect is removed but the lagged dependent variable is still correlated with the new error term. Such endogeneity problems are also solved by the GMM estimations. Both difference GMM and system GMM are designed to remove the dynamic panel bias (Arellano \& Bond, 1991; Arellano \& Bover, 1995; Holtz-Eakin, Newey, \& Rosen, 1988) through instrumental variables. However, the system GMM is an extended form of difference GMM and is more reliable in estimating robust results.

Generalized method of moments is a popular econometric trick designed for a short time dimension with a large number of cross sectionals' panel, and where all the independent variables are not strictly exogenous. It is precisely the case in our sample where $\mathrm{T}=10$ and $\mathrm{N}=17$. In order to elude the problem of dynamic panel bias and endogeneity in autoregressive panel data, this study uses system GMM proposed by Arellano and Bover (1995) and Blundell and Bond (1998). To ensure reliable estimation results, the number of instruments does not exceed the number of cross sections (companies) over the study period in all specifications (Roodman, 2006). Literature has shown that the system GMM estimator has a lower bias and higher efficiency than all the other estimators, including the standard first-differences GMM estimator (Soto, 2009).

$74 \sim$ Nepalese Journal of Insurance and Social Security 
In order to check the fitness of GMM specification models, we apply two specification tests suggested by Arellano and Bond (1991), Arellano and Bover (1995) and Blundell and Bond (1998). First, we perform the over-identifying restrictions test via Sargan specification to check the validity of the instruments used as the moment conditions. Second, we test the fundamental assumption of serial uncorrelated error.

\subsection{Data analysis and presentation}

The study used EViews 9, Stata 14 statistical package and Microsoft Excel 2016 for data analyses and presentation of the study findings. Quantitative data was analyzed using descriptive statistics, which included measures of tendencies (mean, median) and measures of dispersion (standard deviation and range). Inferential statistics involved measurement and relationship, which included correlation and regression.

\subsection{Trend analysis}

A trend is the general direction the market is taking during a specified time period. Trend analysis attempts to predict and examine the movement of position/ status of a market over a period. We carried out trend analyses for each of the eight industry-related variables. The trend analyses were divided into (1) individual companies' trend analysis and (2) industry average trend analysis for each variable.

\section{Results and discussion}

\subsection{Descriptive statistics}

The study variables were collected on an annual basis. All the data used for this study are secondary. LR, RR, SR, ROA are in percentage whereas LF, NW, TPI \& FPI are amount in millions. Table 3 describes the basic features of the variables. Descriptive statistics provide summaries about the sample and they form a fundamental basis for every quantitative data analyses.

The lapse rate of the insurance companies over the study period range from 0 to $101.78 \%$ with a mean of $23.91 \%$ and a standard deviation of $19.76 \%$. The revival rate over the study period 
Volume 3 Issue $3 \quad$ Dec $2020 \quad$ 2565-4942 (Print) 2738-9693 (online)

range from 0 to $539.49 \%$ with a mean of $88.82 \%$ and a standard deviation of $135.64 \%$. The ROA ranges from 0.79 to $21.47 \%$ with a mean of $2.64 \%$ and a standard deviation of $4.02 \%$. The TPI, which refers to the average collected saving from ordinary people, range from 77.27 to23111.02 million Nepalese Rupees with a mean of 2283.02 million and a standard deviation of 3437.34 million. The NW over the study period range from 73.50 million to 9568.52 million Nepalese Rupees with a mean of 1382.49 million and a standard deviation of 14853.98 million.

$76 \sim$ Nepalese Journal of Insurance and Social Security 
Volume 3 Issue 3 Dec $2020 \quad$ 2565-4942 (Print) 2738-9693 (online)

1 Table 3: Descriptive statistics.

\begin{tabular}{lrrrrrrrr}
\hline Variables & FPI & TPI & LF & NW & LR & ROA & RR & SR \\
\hline Mean & 876.17 & 2283.02 & 7607.66 & 1382.49 & 23.91 & 2.64 & 88.82 & 3.83 \\
Median & 463.17 & 1321.98 & 3036.61 & 989.53 & 21.01 & 0.07 & 33.10 & 2.30 \\
Maximum & 9263.43 & 23111.02 & 65451.16 & 9568.52 & 101.78 & 21.47 & 539.49 & 20.41 \\
Minimum & 56.00 & 77.27 & 16.89 & 73.50 & 0.00 & -0.79 & 0.00 & 0.00 \\
Std. Dev. & 1347.54 & 3437.72 & 12207.04 & 1485.98 & 19.76 & 4.02 & 135.64 & 4.57 \\
Skewness & 3.64 & 3.59 & 2.71 & 3.64 & 0.94 & 1.87 & 1.92 & 1.56 \\
Kurtosis & 19.18 & 18.44 & 10.66 & 18.42 & 4.12 & 7.17 & 5.61 & 5.24 \\
Jarque-Bera & 1284.67 & 1184.21 & 356.07 & 1175.63 & 19.64 & 125.73 & 83.38 & 60.40 \\
Probability & 0.00 & 0.00 & 0.00 & 0.00 & 0.00 & 0.00 & 0.00 & 0.00 \\
Sum & 85864.24 & 223735.60 & 737942.80 & 134101.9 & 2342.73 & 253.59 & 8260.50 & 375.68 \\
Sum Sq. Dev. & 176000000 & 1150000000 & 14300000000 & 212000000 & 37866.89 & 1538.35 & 1692647 & 2025.29 \\
Observations & 98 & 98 & 97 & 97 & 98 & 96 & 93 & 98 \\
\hline
\end{tabular}




\subsection{Trend analysis}

\subsubsection{Company average trend analysis}

Table 4 show the average NW, LF, TPI and FPI of individual life insurance company over ten years (2010-2019) period.

Table 4: Average NW, LF, TPI and FPI of 17insurance companies in Nepal.

\begin{tabular}{|c|c|c|c|c|c|}
\hline S.N. & Company Name & NW & $\mathbf{L F}$ & TPI & FPI \\
\hline 1 & Asian Life & 817.73 & $5,360.01$ & $1,851.06$ & 607.89 \\
\hline 2 & Citizen Life & $1,972.96$ & 376.50 & 565.58 & 522.83 \\
\hline 3 & Gurash Life & 665.76 & $1,907.31$ & 733.23 & 275.22 \\
\hline 4 & IME Life & $1,601.00$ & 437.00 & 728.00 & 628.50 \\
\hline 5 & Jyoti Life & $1,756.80$ & 435.46 & 651.30 & 571.93 \\
\hline 6 & LIC Nepal & $1,220.17$ & $22,382.43$ & $4,832.65$ & $1,704.74$ \\
\hline 7 & Met Life & 854.52 & $9,863.63$ & $2,062.33$ & 422.52 \\
\hline 8 & National Life & $1,316.87$ & $3,091.36$ & $1,095.16$ & 402.01 \\
\hline 9 & Nepal Life & $3,636.17$ & $26,303.55$ & $8,692.29$ & $3,410.79$ \\
\hline 10 & Prabhu Life & $1,486.03$ & 207.82 & 294.12 & 264.99 \\
\hline 11 & Prime Life & $1,316.87$ & $3,091.36$ & $1,095.16$ & 402.01 \\
\hline 12 & Reiable Nepal & $1,503.57$ & 352.37 & 431.65 & 391.38 \\
\hline 13 & Reliance Life & $1,572.56$ & 230.43 & 414.00 & 389.81 \\
\hline 14 & Sanima Life & $1,421.30$ & 270.76 & 264.32 & 219.34 \\
\hline 15 & Sun Nepal Life & $1,526.60$ & 387.93 & 537.98 & 451.41 \\
\hline 16 & Surya Life & 746.55 & $1,536.80$ & 842.53 & 307.32 \\
\hline \multirow[t]{2}{*}{17} & Union Life & $1,745.75$ & $1,270.93$ & $1,958.81$ & $1,829.52$ \\
\hline & Industry Average & $1,382.49$ & $7,607.66$ & $2,283.02$ & 876.17 \\
\hline
\end{tabular}

Note: Figures are in million.

Tables 4 provides an overview of NW, LF, TPI and FPI of different insurance companies over the study period. Among the 17 Companies, Nepal life has predominant lead in industry with 3636.17 million net worth, which is more than the industry average. The life fund of Nepal Life is 26303.55 million, which is again 2.63 times more than the industry 
average. Similarly, the total first premium income (TPI) and the first premium income (FPI) are 8692.29 million and 3410.79 million, respectively, which are almost three times higher than the industry average. LIC Nepal and Met Life are, respectively, in the second and third lead in terms of NW, LF, TPI and FPI. The market share of Nepal Life and LIC Nepal together contribute to around more than 50\%. Thus, through the risk management perspective, close watch should be maintained in these companies because if any default occurs in these two companies, it might swap the whole life insurance industry.

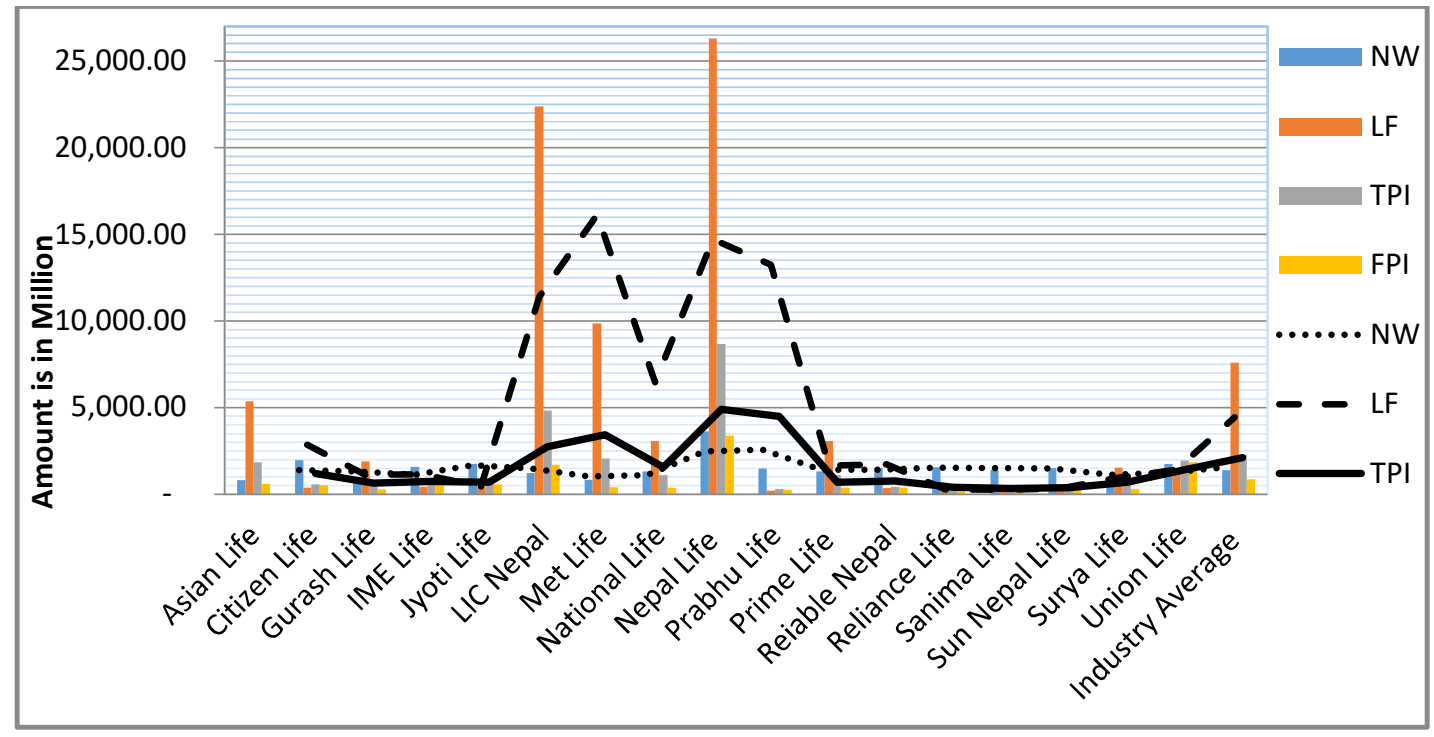

Figure 1. Comparative analyses of NW, LF, TPI and FPI of life insurance companies.

Figure 1 provides a comparative overview of the company's status in term of NW, LF, TPI and FPI.From Figure 1, it is clear that Nepal life, LIC Nepal and Met Life are leading industries. The performance of these three companies is above the industry average for NW, LF, TPI and FPI over the period.

Table 5 shows the comparative overview of companies in terms of ROA, LR, RR and SR over the study period. The ROA of Citizen Life (10.93\%), Asian life (9.17\%) and IME life $(6.49 \%)$ are in the lead. The ROAs of most of the newcomer companies are in sound condition due to lesser amount of total assets in new companies compared to old companies. The reason behind this might be the operation size of companies. Gurash Life has the highest average lapse rate (LR) of $50.81 \%$ and the second highest average revival rate (RR) of $224.59 \%$, which indicates effective renewal of lapse policies over the period. It also has the highest surrender rate (SR) of 3.87\% (see Table 5). 
Volume 3 Issue 3 Dec $2020 \quad$ 2565-4942 (Print) 2738-9693 (online)

Table 5. Average value of ROA, LR, RR and SR of insurance companies in Nepal.

\begin{tabular}{|c|c|c|c|c|c|}
\hline S.N. & Company Name & ROA & $\mathbf{L R}$ & $\mathbf{R R}$ & SR \\
\hline 1 & Asian Life & 9.17 & 21.25 & 1.74 & 2.34 \\
\hline 2 & Citizen Life & 10.93 & 3.19 & 0.00 & 0.00 \\
\hline 3 & Gurash Life & 0.01 & 50.81 & 224.59 & 3.87 \\
\hline 4 & IME Life & 6.49 & 0.81 & 0.00 & 0.00 \\
\hline 5 & Jyoti Life & 0.06 & 0.76 & 0.00 & 0.00 \\
\hline 6 & LIC Nepal & 0.01 & 17.65 & 46.72 & 9.61 \\
\hline 7 & Met Life & 0.08 & 9.16 & 48.07 & 1.45 \\
\hline 8 & National Life & 5.20 & 38.37 & 48.04 & 3.39 \\
\hline 9 & Nepal Life & 0.03 & 18.01 & 349.64 & 9.95 \\
\hline 10 & Prabhu Life & 0.00 & 0.00 & 38.24 & 0.00 \\
\hline 11 & Prime Life & 5.20 & 38.37 & 48.04 & 3.39 \\
\hline 12 & Reiable Nepal & 3.88 & 3.45 & 0.20 & 0.00 \\
\hline 13 & Reliance Life & 3.73 & 1.77 & 50.26 & 0.00 \\
\hline 14 & Sanima Life & 1.04 & 1.72 & 0.00 & 0.01 \\
\hline 15 & Sun Nepal Life & 0.04 & 5.15 & 0.00 & 0.00 \\
\hline 16 & Surya Life & 0.05 & 37.00 & 44.38 & 3.58 \\
\hline \multirow[t]{2}{*}{17} & Union Life & 6.46 & 1.34 & 4.56 & 0.00 \\
\hline & Industry Average & 2.64 & 23.91 & 88.82 & 3.83 \\
\hline
\end{tabular}

Note: Rates are in percentage.

National life and Prime life have the second highest LR followed by Surya Life (third) and Nepal Life (fourth). Of all the companies, Nepal life has the highest revival rate $(349.64 \%)$ and also the highest surrender rate $(9.95 \%)$. The revival rates of most other companies are below the industry average. Nepal Life and LIC Nepal have above industry average surrender rates of $9.95 \%$ and $9.61 \%$, respectively (Table 5). This again raises the question on the efficiency shows by the RR ratio. This might be due to huge number of policy holders across the country. This trend is more evident from Figure 2. 


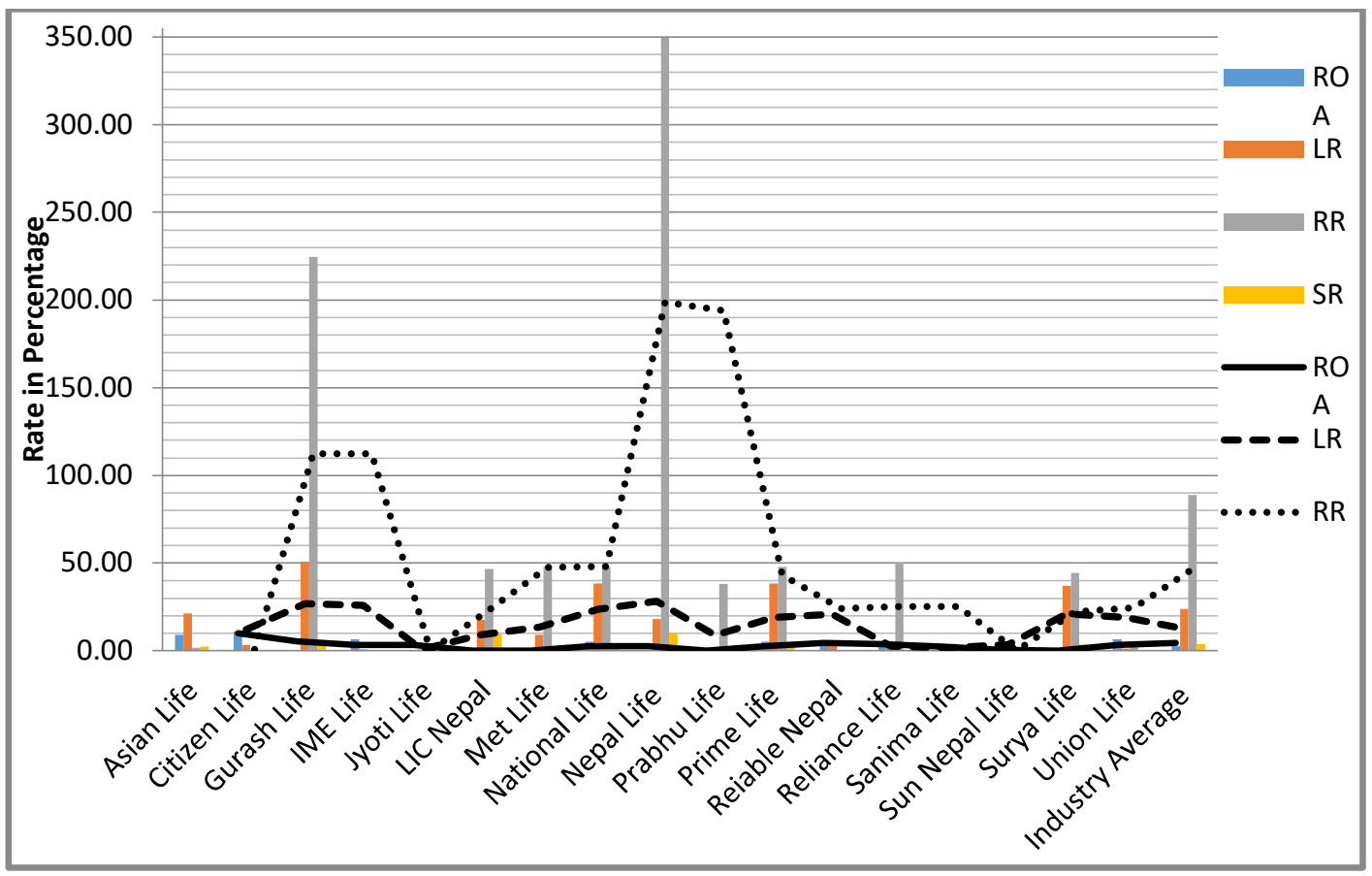

Figure 2. Comparative analyses of ROA, LR, RR and SR of life insurance companies in Nepal.

Nepal Life has the highest RR in industry with below industry average value for LR (18.01\%) indicating efficient renewal of lapse policy. Gurash Life has the highest LR $(50.81 \%)$ with $224.59 \%$ RR and $3.87 \%$ SR indicating its efficiency in recovering lapse policies. Other companies have below industry average values for LR, RR, SR except LIC Nepal and Nepal Life, which have above industry average SR of $9.61 \%$ and $9.95 \%$, respectively (Figure 2).

\subsubsection{Industry average trend analysis}

Table 6 shows the trend analysis of NW, LF, TPI \& FPI over the 10 years' period in life insurance industry in Nepal. If we observe the life insurance industry over the 10 years' period, we notice 1382.49 million of NW, 7607.66 million of LF, 2283.02 million of TPI and 876.17 million of FPI as the industrial average (Table 6). 
Table 6. Trend analysis of NW, LF, TPI and FPI of life insurance industry.

\begin{tabular}{rlrrrr}
\hline S.N. & Year (BS) & NW & LF & TPI & FPI \\
\hline 1 & 2066 & 336.18 & 2015.99 & 778.18 & 284.80 \\
2 & 2067 & 380.74 & 2792.68 & 946.92 & 301.93 \\
3 & 2068 & 518.97 & 3722.02 & 1227.99 & 405.61 \\
4 & 2069 & 722.42 & 4957.19 & 1446.63 & 416.58 \\
5 & 2070 & 920.27 & 6393.56 & 1903.74 & 646.08 \\
6 & 2071 & 1062.28 & 8390.83 & 2528.60 & 942.67 \\
7 & 2072 & 1409.34 & 10974.84 & 3243.90 & 1108.26 \\
8 & 2073 & 2076.21 & 13867.14 & 3876.18 & 1202.67 \\
9 & 2074 & 2192.56 & 8348.53 & 2489.29 & 912.96 \\
10 & 2075 & 2338.56 & 10693.99 & 3164.73 & 1639.72 \\
\hline & Industry Average & $\mathbf{1 3 8 2 . 4 9}$ & $\mathbf{7 6 0 7 . 6 6}$ & $\mathbf{2 2 8 3 . 0 2}$ & $\mathbf{8 7 6 . 1 7}$ \\
\hline
\end{tabular}

Note: Figures are in million.

Figure 3 shows the trend of NW, LF, TPI and FPI over the study period. It shows the highest growth of LF and TPI in the year 2073.

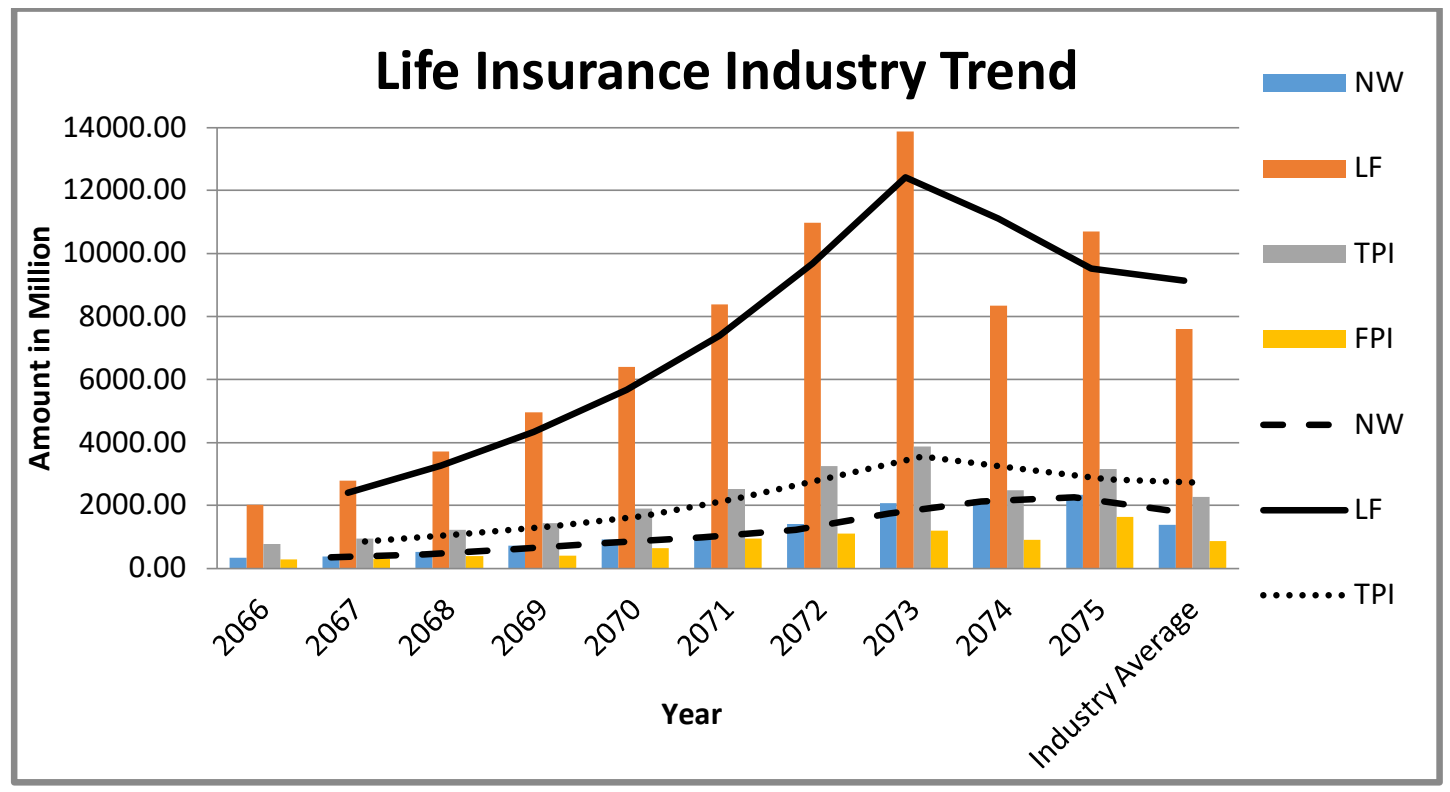

Figure 3. Trend analyses of NW, LF, TPI and FPI of life insurance industry in Nepal.

Looking at Figure 3 and Table 6, it is clear that NW, LF, TPI, FPI is increasing from 2066 BS to 2073 BS, whereas LF became maximum in the year 2073BS and started to fall 
henceforth. This might be due to the addition of 10 new life insurance companies in the market after 2073 BS. Other variables like TPI and FPI are increasing at decreasing rate with respect to the past, whereas NW reached the maximum in the $2075 \mathrm{BS}$ and increasing at decreasing rate. The reason behind this might be full operation of all new life insurance companies in the market after 2075 BS.

In general, the trend shows an overall growth in NW, LF, TPI and FPI over the period. If we examine the trend line in Figure 3, TPI and LF have similar growth pattern over the period. The reason behind this might be the predominant impact of TPI over LF in valuation of life insurance industry and a constant growth of NW over the period.

Table 7: Trend analysis of LR, ROA, RR and SR of life insurance industry

\begin{tabular}{rlrrrr}
\hline S.N. & Year (BS) & LR & ROA & RR & SR \\
\hline 1 & 2066 & 27.48 & 1.98 & 43.65 & 2.63 \\
2 & 2067 & 32.18 & 5.31 & 46.81 & 2.22 \\
3 & 2068 & 32.87 & 2.67 & 57.78 & 2.94 \\
4 & 2069 & 37.04 & 4.14 & 85.17 & 4.92 \\
5 & 2070 & 30.17 & 2.38 & 110.35 & 5.27 \\
6 & 2071 & 32.23 & 1.53 & 114.42 & 5.24 \\
7 & 2072 & 30.32 & 2.16 & 125.82 & 5.47 \\
8 & 2073 & 29.91 & 1.97 & 115.92 & 6.40 \\
9 & 2074 & 11.53 & 2.48 & 87.58 & 2.91 \\
10 & 2075 & 7.59 & 2.48 & 94.72 & 2.68 \\
\hline & Industry Average & $\mathbf{2 3 . 9 1}$ & $\mathbf{2 . 6 4}$ & $\mathbf{8 8 . 8 2}$ & $\mathbf{3 . 8 3}$ \\
\hline
\end{tabular}

Note: Rates are in percentage.

Table 7 shows the trend of LR, ROA, RR and SR over the period and the overall industry average of these variables. Table 7 shows $23.91 \%$ LR, $2.641 \%$ ROA, $88.82 \%$ RR and $3.83 \%$ SR as the industry average. This indicates that the industry has $23.91 \%$ lapse rate over the period with an average profitability of $2.64 \%$. Similarly, industry has $88.82 \%$ of RR over the LR and $3.83 \%$ SR. Table 7 also shows overall industry trend of LR, SR, RR and ROA over the period. This trend is more clearly elucidated in Figure 4. 


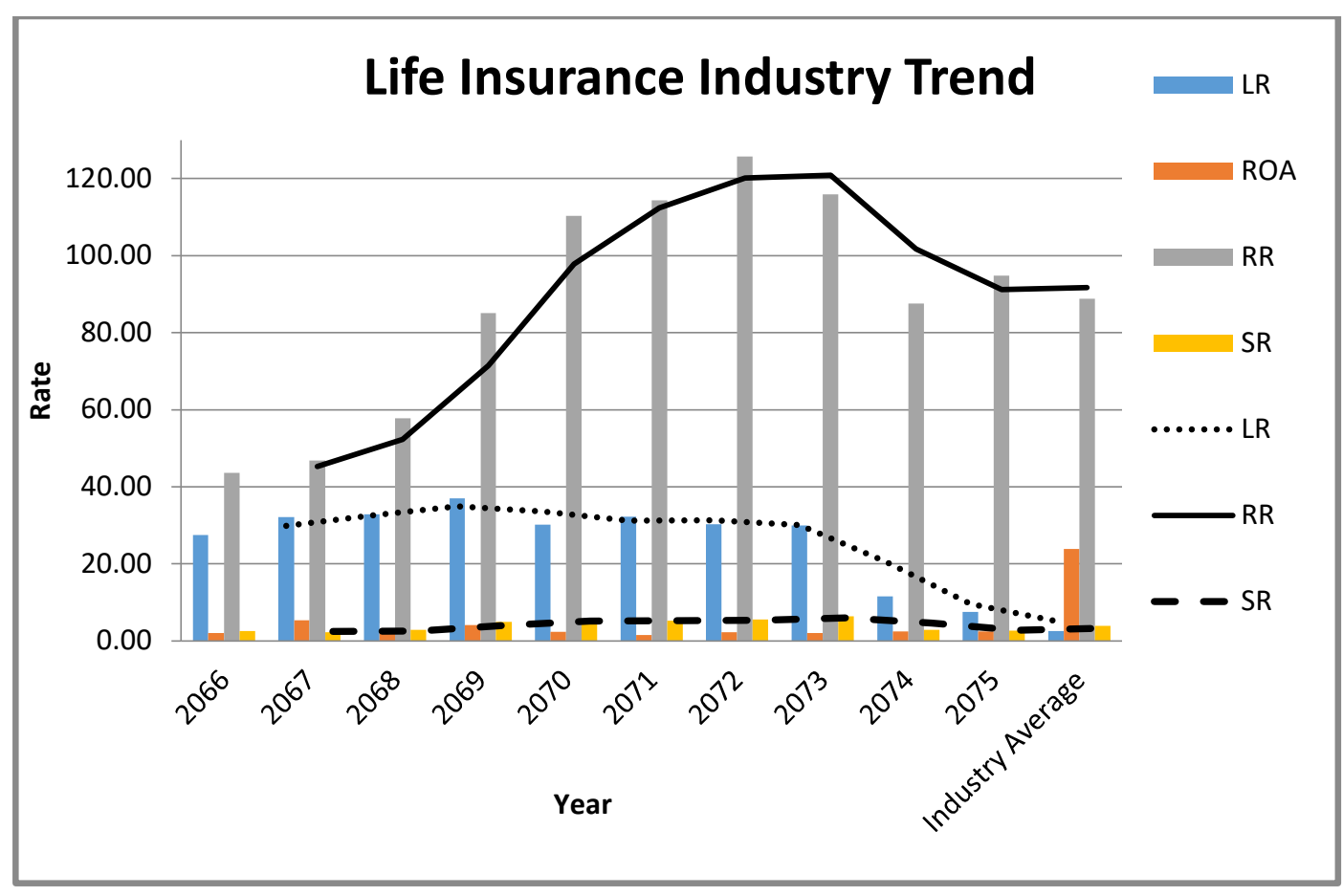

Figure 4: Trend analyses of LR, RR, ROA and SR in life insurance industry in Nepal.

If we examine the RR curve, it is increasing at increasing rate till 2070BS and increasing at decreasing rate till 2072BS reaching a maximum in 2073-74BS after which it started to decrease. The reason of this behavior of the RR curve might be due to the behavior of the LR curve, which shows an increasing trend till 2069 BS and constantly decreasing trend till 2073 BS and rapidly decreasing trend post 2074 BS. The reason behind overall behavior of the RR and LR curves might be due to the increasing awareness of life insurance industry followed by the realization on the importance of life insurance by the Nepalese following huge casualties due to the devastating earthquake in 2071 BS. Apart from that, the strong presence of regulatory authority and insurance company might be another reason.

If we examine the SR cure, it has slow growth rate of $11.78 \%$ till $2069 \mathrm{BS}$ and rapid growth rate at $67.34 \%$ from $2069 \mathrm{BS}$ to $2070 \mathrm{BS}$ and a constant growth rate of $21.4 \%$ from 2071BS to $2073 \mathrm{BS}$ and rapid fall at 58.12\% from $2074 \mathrm{BS}$ onwards. Overall, the SR rate of all insurance companies is falling down in life insurance industry. This might be due to the strong presence of regulatory authority as well as insurance awareness amongst policyholders. 


\subsection{Empirical estimation results}

The empirical estimation results are reported in Table 8. The lagged value of each variable (NW, ROA, LF and TPI) was strongly positively significant in all models, which confirms the presence of strong persistence of these variables. The result showed that the previous years' values explained over $77 \%$ of the current value, which indicates that the NW, ROA, LF and TPI shock likely has a prolonged effect in the insurance industry.

Table 8.GMM estimation results of four response variables against their respective lagged values and the lapse rate (LR).

\begin{tabular}{llr}
\hline Response variables & Predictor variables & Statistics \\
\hline Net Worth (NW) & Lapse rate & $0.06756(0.94)$ \\
& Lagged NW & $0.9867613 * * *(25.06)$ \\
& Sargan test p-value & 0.9606 \\
& A-B AR (2) test p-value & 0.2691 \\
\hline Life Fund (LF) & Lapse rate & $-0.1474065 * * *(-2.76)$ \\
& Lagged LF & $0.8620322 * * *(40.75)$ \\
& Sargan test p-value & 0.9917 \\
& A-B AR (2) test p-value & 0.9604 \\
\hline Profitability (ROA) & Lapse rate & $0.0641996 * * *(12.28)$ \\
& Lagged ROA & $0.7772652 * * *(64.93)$ \\
& Sargan test p-value & 0.9295 \\
& A-B AR (2) test p-value & 0.4927 \\
\hline Total Premium Income & Lapse rate & $-0.19244 * *(-2.33)$ \\
& Lagged TPI & $0.849579 * * *(35.63)$ \\
& Sargan test p-value & 0.9356 \\
& A-B AR (2) test p-value & 0.596 \\
\hline
\end{tabular}

Notes: z-statistics are given in parentheses. **significant at a level 0.05, ***significant at a level 0.01 .

The Sargan Test $\mathrm{p}$-value for all models was more than 0.05 , which indicate highly significant validity of this dynamic GMM model. Moreover, to check the fitness of the 
GMM specification models, we applied two specification tests suggested by Arellano and Bond (1991), Arellano and Bover (1995) and Blundell and Bond (1998) in all models. Result of this test was also positive, stating fitness of the employed GMM model (Table 8).

According to the empirical estimation, the lapse rate was significantly negatively correlated with life fund (LF) and total premium income (TPI) with coefficients of -0.1474065 and0.19244, respectively (Table 8). It might be because higher lapse rate reduces premium income of the insurer, resulting in less life fund provision. Similarly, higher lapse rate indicates that many people are not renewing their insurance contracts resulting in lesser TPI.

The lapse rate (LR) was significantly positively correlated with profitability (ROA). It is because, lapse rate refers to failure to pay premium or failure to continue the risk coverage of policy. Therefore, lower the provision of unexpired risk and life fund, higher is the profitability. Moreover, due to increased lapse rate, insurers are getting fund to invest with less expenses (less unexpired risk Provision/Life fund to policyholder). Apart from that, ROA has several other internal and external impacting factors, such as productivity, operation efficiency and investment opportunity.

The empirical estimation results for revival rate are reported in Table 9. The revival rate is significantly positively correlated with the profitability (ROA). The reason behind this might be that higher revival rate indicates higher renewal income resulting in more funds available for investment, thereby bringing positive cash inflow for the company. However, the revival rate did not show any significant association with net worth (NW), life fund (LF) and total premium income (TPI) (Table 9).

$72 \sim$ Nepalese Journal of Insurance and Social Security 
Table 9: GMM estimation results of four response variables against their respective lagged values and the revival rate (RR).

\begin{tabular}{llr}
\hline Response variables & Predictor variables & Statistics \\
\hline Net Worth (NW) & Revival rate & $-0.05359(-0.68)$ \\
& Lagged NW & $1.068807 * * *(16.62)$ \\
& Sargan test p-value & 0.9339 \\
& A-B AR (2) test p-value & 0.3287 \\
\hline Life Fund (LF) & Revival rate & $-0.0167(-1.09)$ \\
& Lagged LF & $1.039614 * * *(95.86)$ \\
& Sargan test p-value & 0.9759 \\
& A-B AR (2) test p-value & 0.0424 \\
\hline Profitability (ROA) & Revival rate & $0.031503 * * *(15.39)$ \\
& Lagged ROA & $0.910329 * * *(39.99)$ \\
& Sargan test p-value & 0.9399 \\
& A-B AR (2) test p-value & 0.4754 \\
\hline Total Premium Income (TPI) & Revival rate & $-0.01109(-0.65)$ \\
& Lagged TPI & $1.047954 * *(23.24)$ \\
& Sargan test p-value & 0.9398 \\
& A-B AR (2) test p-value & 0.2132 \\
\hline
\end{tabular}

Notes: z-statistics are given in parentheses. ****significant at a level 0.01 .

\section{Conclusion and recommendations}

The study was conducted with a view to examine the impact of lapse rate and revival rate on net worth, profitability, life fund, and total Premium income of life insurance industry of Nepal over the period of 2010 -2019AD. The study found $23.91 \%$ lapse rate, $2.64 \%$ ROA, $88.82 \%$ revival rate and $3.83 \%$ surrender rate over the period. The lapse rate is significantly negatively correlated with life fund (LF) and total premium income (TPI) with the model coefficients of -0.1474065 and -0.19244 , respectively. This might be because higher lapse rate reduces the premium income of the insurer, resulting in less life fund provision. Similarly, higher lapse rate indicates that lots of people are not renewing their insurance contract resulting in lesser the TPI. Moreover, the empirical estimation shows that the lapse rate (LR) has a significant positive association with profitability (ROA). This might be because high lapse rate lowers the provision of unexpired risk and life fund resulting in higher amount of profitability. The revival rate is significantly positively correlated with the profitability (ROA). This might be because a higher revival rate increases the renewal income of a company resulting in more funds available for 
investment for insurer thereby bringing a positive cash inflow for the company. However, the revival rate does not show any significant association with net worth (NW), life fund (LF) and total premium income (TPI).

This study gives strong foundation to guide policy in the areas of risk management and good governance in life insurance industry. Moreover, it gives a clearer picture of the Nepalese life insurance industry in terms of Lapse rate, revival rate, surrender rate, net worth, life fund, total premium income and first premium income. The findings enable concerned stakeholders to make strategies to invest and operate effectively in life insurance market. It also provides value addition to the regulators for risk-based supervision and enables them to locate the risk factor associated with lapse rate and surrender rate in the life insurance industry. The findings might be equally useful to the insurance companies to understand the contemporary conditions and emerging trends of surrender rate, lapse rate and revival rate. This makes them understand their real position in the market. This might help them to build strategic plans to improve operation their overall functioning. The study like this is expected to create awareness among the general readers and public about the importance of life insurance industries. This knowledge might inspire general public to increase investment in life insurance companies by purchasing life insurance policies or sharing investment in life insurance companies. There may be other behavioral and cognitive factors influencing lapse rate as well and profitability, Net-worth and life fund. For example, the policyholder behavior as well as people and organizational behavior, efficiency, strategic planning may also have also influenced the lapse rate, Net-worth, profitability, Life fund, revival rate as son. However, these factors are not covered in the current study. The behavioral impact of lapse policy on Life Insurance Company might be another topic for future research.

$74 \sim$ Nepalese Journal of Insurance and Social Security 


\section{Reference}

Arellano, M., \& Bond, S. (1991). Some tests of specification for panel data: Monte Carlo evidence and an application to employment equations. The Review of Economic Studies, 58(2), 277-297.

Arellano, M., \& Bover, O. (1995). Another look at the instrumental variable estimation of error-components models. Journal of Econometrics, 68(1), 29-51.

Baltagi, B. (2008). Econometric analysis of panel data (4th Revised ed.): John Wiley \& Sons.

Belth, J. M. (1968). The impact of lapse rates on life insurance prices. Journal of Risk and Insurance, 35(1), 17-34.

Blundell, R., \& Bond, S. (1998). Initial conditions and moment restrictions in dynamic panel data models. Journal of Econometrics, 87(1), 115-143.

Bond, S. R. (2002). Dynamic panel data models: A guide to micro data methods and practice. Portuguese Economic Journal, 1(2), 141-162.

Fier, S. G., \& Liebenberg, A. P. (2013). Life insurance lapse behavior. North American Actuarial Journal, 17(2), 153-167.

Holtz-Eakin, D., Newey, W., \& Rosen, H. S. (1988). Estimating vector autoregressions with panel data. Econometrica, 56(6), 1371-1395.

Kiesenbauer, D. (2012). Main determinants of lapse in the German life insurance industry. North American Actuarial Journal, 16(1), 52-73.

Kuo, W., Tsai, C., \& Chen, W. K. (2003). An empirical study on the lapse rate: The cointegration approach. Journal of Risk and Insurance, 70(3), 489-508.

Levin, A., Lin, C.-F., \& Chu, C.-S. J. (2002). Unit root tests in panel data: Asymptotic and finite-sample properties. Journal of Econometrics, 108(1), 1-24.

Malik, H. (2011). Determinants of insurance companies profitability: an analysis of insurance sector of Pakistan. Academic Research International, 1(3), 315-321. 
Volume $3 \quad$ Issue $3 \quad$ Dec $2020 \quad$ 2565-4942 (Print) 2738-9693 (online)

Mall, S., \& Sahoo, S. (2015). Determinants of lapsation of life insurance policies: an empirical investigation for the Indian market. International Journal of Financial Services Management, 8(2), 133-147.

Nickell, S. (1981). Biases in dynamic models with fixed effects. Econometrica, 49(6), 1417-1426.

Parihar, S. S. (2020). Lapsation and sum assured of life insurance sector in India. Prestige International Journal of Management and Research, 12(1/2), 211-216.

Poufinas, T., \& Michaelide, G. (2018). Determinants of Life Insurance Policy Surrenders. Modern Economy, 9(8), 1400-1422.

Roodman, D. (2006). How to do xtabond2: An introduction to 'difference'and 'system GMM in stata. Center for Global Development Working Paper No. 103.

Smith, M. L. (1982). The life insurance policy as an options package. Journal of Risk and Insurance, 49(4), 583-601.

Soto, M. (2009). System GMM estimation with a small sample. Institut d'Anàlisi Econòmica (CSIC) Working Paper 780.09.

Subashini, S., \& Velmurugan, R. (2015). Lapsation in Life Insurance Policies. International Journal, 3(4), 29-39.

Subashini, S., \& Velmurugan, R. (2016). A study on lapsation of insurers in life insurance policies in Coimbatore. International Journal of Management Research and Reviews, 6(5), 560.

Vidyavathi, K. (2013). Lapsation of life insurance policies: Literature review. ZENITH International Journal of Business Economics \& Management Research, 3(11), 134141.

Ward, D., \& Zurbruegg, R. (2000). Does insurance promote economic growth? Evidence from OECD countries. Journal of Risk and Insurance, 67(4), 489-506.

Yu, L., Cheng, J., \& Lin, T. (2019). Life insurance lapse behaviour: evidence from China. The Geneva Papers on Risk and Insurance-Issues and Practice, 44(4), 653-678.

$76 \sim$ Nepalese Journal of Insurance and Social Security 